\title{
Differential sensitivity of RIP3-proficient and deficient murine fibroblasts to camptothecin anticancer drugs
}

Jin-xue HE\#, Ying-qing WANG", Jian-ming FENG, Jia-xin LI, Lei XU, Xiao-hua LI, Wei WANG, Xia-juan HUAN, Yi JIANG, Bing YU, Guang CHEN, Ze-hong MIAO*

Division of Anti-Tumor Pharmacology, State Key Laboratory of Drug Research, Shanghai Institute of Materia Medica, Chinese Academy of Sciences, Shanghai 201203, China

Acta Pharmacologica Sinica (2012) 33: 426-428; doi: 10.1038/aps.2012.1; published online 23 Jan 2012

\section{Dear Editor,}

Receptor-interacting protein 3 (RIP3) is a serine/threonine protein kinase, which has extensive substrates including its cognate kinase RIP1 and multiple metabolic enzymes involving oxidative phosphorylation ${ }^{[1,2]}$. RIP3 has been shown to be essential for development, immunity and some physiological or pathophysiological responses to exogenous and endogenous stimuli ${ }^{[3-5]}$. In 2009, three groups independently reported that RIP3 acted as a molecular switch between apoptosis and necrosis (also called as necroptosis) ${ }^{[6-8]}$. Specifically, RIP3 could turn tumor necrosis factor (TNF)-induced cell death from apoptosis to necrosis ${ }^{[6]}$. Most of small-molecule anticancer drugs elicit their anticancer effects via apoptotic induction $^{[9]}$. However, it is unclear whether RIP3 affects the cellular sensitivity to small-molecule anticancer drugs.

We treated A cells (NIH $3 \mathrm{~T} 3$ cells, murine fibroblasts, $\mathrm{RIP3}^{-/-}$; typically undergoing apoptosis in response to TNF stimulation) and N cells (NIH 3T3 cells, murine fibroblasts, $\mathrm{RIP}^{+/+}$; undergoing necroptosis in response to TNF stimulation ${ }^{[6]}$ with small-molecule anticancer drugs of different mechanisms of action. Detection by sulforhodamine B assays showed that A cells and $\mathrm{N}$ cells displayed differential sensitivity only to the examined topoisomerase I (Top1) inhibitors camptothecins. RIP3-deficient A cells revealed 32.6- and 40.2fold higher sensitivity than RIP3-proficient N cells to SN38 and chimmitecan ${ }^{[10]}$, respectively (Figure 1A). Such differen-

\footnotetext{
"These authors contributed equally to this work.

* To whom correspondence should be addressed.

E-mail zhmiao@mail.shcnc.ac.cn

Received 2011-12-31 Accepted 2012-01-05
}

tial sensitivity was reflected as higher apoptosis rates (Figure 1B) and more rapid $\mathrm{G}_{2} / \mathrm{M}$ arrest (Figure $1 \mathrm{C}$ ) in A cells than in $\mathrm{N}$ cells treated with chimmitecan. Consistently, exposure to chimmitecan caused faster reduction of the target protein Top1 in A cells than in N cells (Figure 1D); and the treatment with chimmitecan or SN38 drove more $\gamma-\mathrm{H} 2 \mathrm{AX}$ formation (a molecular marker for DNA double-strand breaks; Figure 1E) and produced more foci of phosphorylated ataxia telangiectasia mutated kinase (p-ATM) at Ser 1981 (sensing DNA double-strand breaks; Figures 1F and 1G) in A cells than in N cells. These results collectively indicate that the differential sensitivity of the RIP3-deficient A cells and the RIP3-proficient $\mathrm{N}$ cells to the examined Top1 inhibitors in all the tested events from inducing DNA double-strand breaks through sensing the damage signals to eliciting the final biological effects including cell cycle arrest, apoptosis and proliferation/growth inhibition.

Both A cells and $\mathrm{N}$ cells were kindly gifted from Prof Jiahuai HAN, who used them to successfully demonstrate the role of RIP3 in regulating TNF-inducing cell death ${ }^{[6]}$. The differential sensitivity of the RIP3-deficient and proficient murine fibroblasts to the Top1 inhibitors suggests a role of RIP3 in determining the cellular sensitivity to those agents. In this case, however, RIP3 does not seem to directly affect the choice of cell death between apoptosis and necrosis, because no significant difference of the cellular sensitivity to the other examined anticancer drugs except camptothecins was detectable (data not shown) and because RIP3-based differential responses of A cells and $\mathrm{N}$ cells to the Top1 inhibitors took place actually at the levels of the target protein Top1 and DNA double-strand breaks, not only at the level of cell death. In contrast, our data seem to imply that RIP3 is involved in the DNA damage 
A
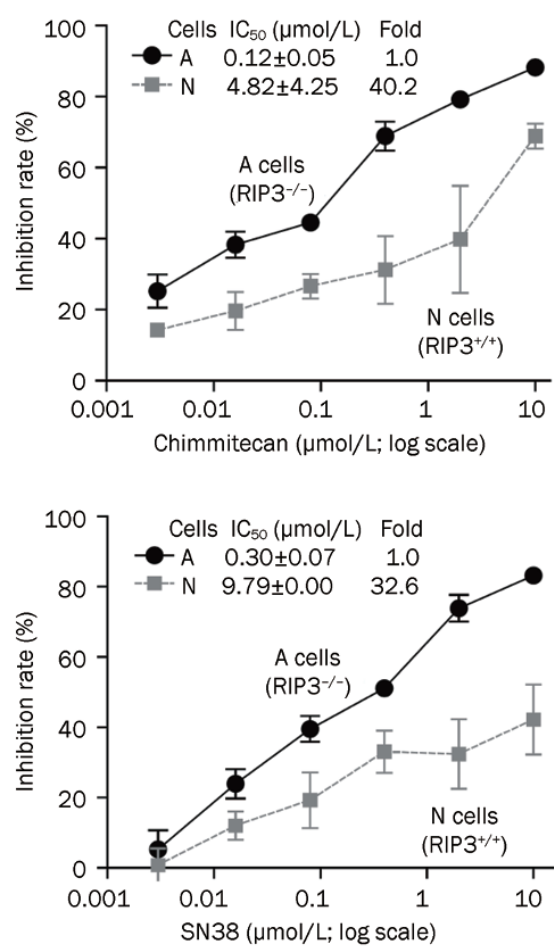

E

\begin{tabular}{llllll}
\multicolumn{8}{c}{ Chimmitecan (1 h; nmol/L) } \\
\hline 16 & 400 & 10000 & 16 & 400 & 10000
\end{tabular}

$\mathrm{y}-\mathrm{H} 2 \mathrm{AX}$

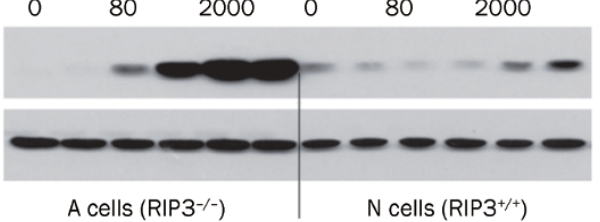

SN38 (1 h; nmol/L)
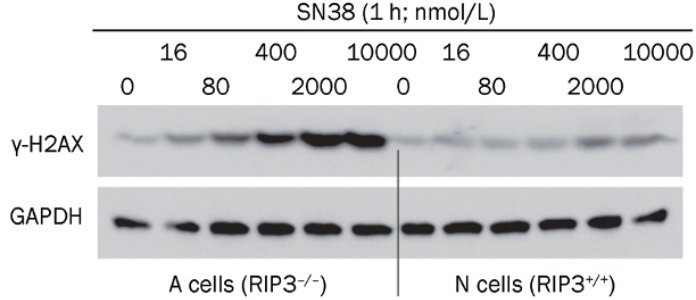

B

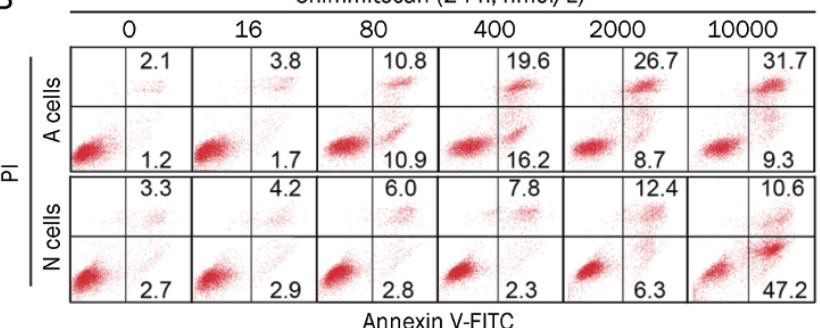

C

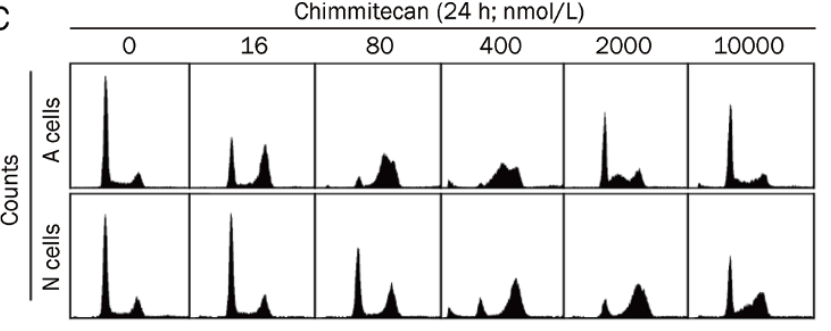

DNA content (FL2-A)

D

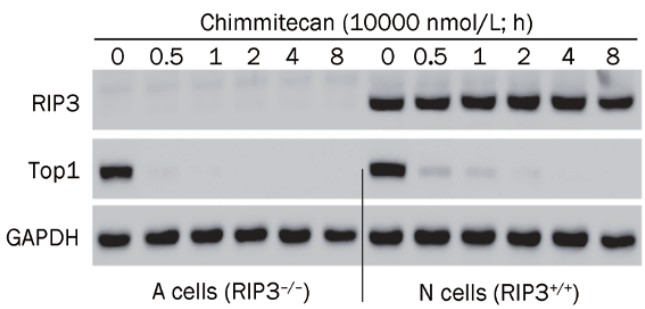

$\mathrm{F}$

Chimmitecan (1 h; nmol/L)
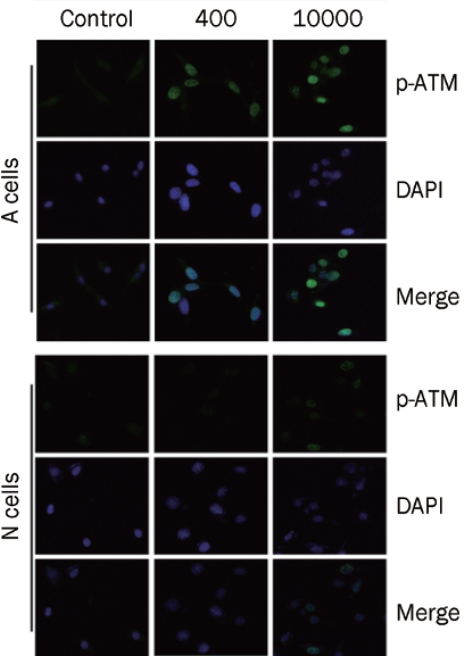

G Chimmitecan (1 h; $10000 \mathrm{nmol} / \mathrm{L})$

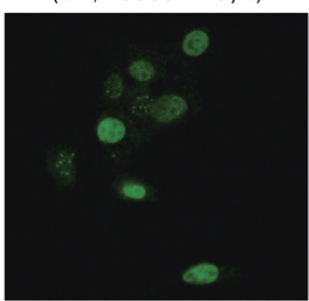

A cells (RIP3-/-)

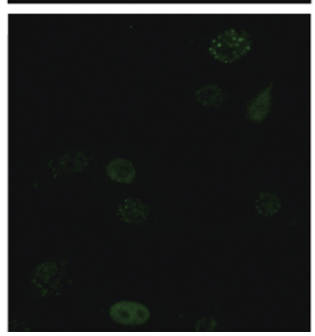

$\mathrm{N}$ cells $\left(\right.$ RIP3 $^{+/+}$)

Figure 1. Differential sensitivity of RIP3-deficient A cells and RIP3-proficient $\mathrm{N}$ cells to camptothecins. (A) A cells and $\mathrm{N}$ cells displayed differential sensitivity to camptothecins. A cells (RIP3 $\left.{ }^{-/}\right)$and $\mathrm{N}$ cells $\left(\mathrm{RIP}^{+/+}\right)$were treated with gradient concentrations of chimmitecan or SN38 $(10,2,0.4,0.08$, 0.016 , and $0.0032 \mu \mathrm{mol} / \mathrm{L})$ for $72 \mathrm{~h}$. Cell viability was then determined by sulforhodamine $B$ assays. The $\mathrm{IC}_{50}$ value was calculated by SoftMax ${ }^{\circledR}$ Pro Software and the data from three independent experiments were presented as mean \pm SD. (B) Exposure to chimmitecan for $24 \mathrm{~h}$ resulted in higher apoptosis rates in A cells. Both A cells and $\mathrm{N}$ cells were treated with the indicated concentrations of chimmitecan or vehicle for $24 \mathrm{~h}$, then stained with an annexin $\mathrm{V}$ antibody and propidium iodide (PI), and analyzed by flow cytometry. The numbers represent apoptotic percentages. (C) Exposure of A cells and $\mathrm{N}$ cells to chimmitecan for $24 \mathrm{~h}$ induced $\mathrm{G}_{2} / \mathrm{M}$ arrest. Both cells were treated with chimmitecan or vehicle for $24 \mathrm{~h}$, fixed, stained with PI, and analyzed by flow cytometry. (D) Faster reduction of Top1 protein in A cells. Cells were treated with $10000 \mathrm{nmol} / \mathrm{L}$ chimmitecan for the indicated times. Total cell lysates were collected and subjected to SDS-PAGE gels for Western blotting analyses. The protein levels of RIP3, Top1, and GAPDH were determined. (E) Faster formation of $\mathrm{y}-\mathrm{H} 2 \mathrm{AX}$ in A cells. The levels of $\mathrm{y}-\mathrm{H} 2 \mathrm{AX}$ were detected by Western blotting at $1 \mathrm{~h}$ after the treatment with camptothecins. (F) Higher levels of p-ATM at Ser1981 in A cells in responding to the treatment with chimmitecan. Cells were treated with chimmitecan $(400 \mathrm{nmol} / \mathrm{L}$ and $10000 \mathrm{nmol} / \mathrm{L})$ or vehicle for $1 \mathrm{~h}$, fixed and stained with a specific antibody against the phosphorylated ATM at Ser1981 of (p-ATM, green foci) for fluorescence microscopy analyses. Nuclei were identified by DAPI (4,6 diamidino-2-phenylindole) counterstaining (blue). (G) Enlarged images of $\mathrm{p}$-ATM at $10000 \mathrm{nmol} / \mathrm{L}$ chimmitecan in Figure 1F. 
induced by the Top1 inhibitors and/or subsequent repair. As a clinically important class of anticancer drugs, Top1 inhibitors are extensively used to treat various solid tumors such as colon and lung cancers. Occurrence of drug resistance to those inhibitors is a serious obstacle to successful therapy in the clinic ${ }^{[11]}$. The differential sensitivity of A cells and $\mathrm{N}$ cells to SN38 and chimmitecan also suggests that RIP3 could contribute to cellular resistance to Top1 inhibitors. Actually, we detected and found that RIP3 was expressed at high levels in cancer cells originated from different human tissues including blood (K562), liver (SMMC-7402 and SMMC-7721), colon (HCT116), stomach (MKN45), lung (A549), breast (MDAMB-468, MDA-MB-231, T47D, and BT549), cervix (HeLa) and bone (Rh30) (data not shown). Inhibition of RIP3 might be an alternative approach to circumventing drug resistance. However, the exact molecular mechanisms remain to be further clarified.

Taken together, our results demonstrate for the first time the differential sensitivity of the RIP3-deficient A cells and the RIP3-proficient $\mathrm{N}$ cells to Top1 inhibitors, suggesting a potential new role of RIP3 in Top1 inhibitor-induced DNA damage/ repair and cellular resistance to Top1 inhibitors, probably independently of its regulation in the choice of cell death modes.

\section{Acknowledgements}

We thank Prof Jia-huai HAN (Xiamen University, China) for his kind gifts of RIP3-deficient A cells and RIP3-proficient N cells. This work was supported by grants from the National Natural Science Foundation of China (№ 81025020 and № 81021062), the National Basic Research Program of China (№ 2012CB932502), the National Science \& Technology Major Project of China (№ 2012ZX09301-001-002) and the State Key Laboratory of Drug Research of China (№ SIMM1105KF-02).

\section{References}

1 Vandenabeele P, Galluzzi L, Vanden Berghe T, Kroemer G. Molecular mechanisms of necroptosis: an ordered cellular explosion. Nat Rev Mol Cell Biol 2010; 11: 700-14.

2 Zhang DW, Zheng M, Zhao J, Li YY, Huang Z, Li Z, et al. Multiple death pathways in TNF-treated fibroblasts: RIP3- and RIP1-dependent and independent routes. Cell Res 2011; 21: 368-71.

3 Oberst A, Dillon CP, Weinlich R, McCormick LL, Fitzgerald P, Pop C, et al. Catalytic activity of the caspase-8-FLIP(L) complex inhibits RIPK3dependent necrosis. Nature 2011; 471: 363-7.

4 Kaiser WJ, Upton JW, Long AB, Livingston-Rosanoff D, Daley-Bauer LP, Hakem R, et al. RIP3 mediates the embryonic lethality of caspase-8deficient mice. Nature 2011; 471: 368-72.

5 Lu JV, Weist BM, van Raam BJ, Marro BS, Nguyen LV, Srinivas P, et al. Complementary roles of Fas-associated death domain (FADD) and receptor interacting protein kinase-3 (RIPK3) in T-cell homeostasis and antiviral immunity. Proc Natl Acad Sci U S A 2011; 108: 15312-17.

6 Zhang DW, Shao J, Lin J, Zhang N, Lu BJ, Lin SC, et al. RIP3, an energy metabolism regulator that switches TNF-induced cell death from apoptosis to necrosis. Science 2009; 325: 332-6.

7 He S, Wang L, Miao L, Wang T, Du F, Zhao L, et al. Receptor interacting protein kinase-3 determines cellular necrotic response to TNFalpha. Cell 2009; 137: 1100-11.

8 Cho YS, Challa S, Moquin D, Genga R, Ray TD, Guildford M, et al. Phosphorylation-driven assembly of the RIP1-RIP3 complex regulates programmed necrosis and virus-induced inflammation. Cell 2009; 137: 1112-23.

9 Fulda S, Debatin KM. Extrinsic versus intrinsic apoptosis pathways in anticancer chemotherapy. Oncogene 2006; 25: 4798-811.

10 Huang M, Miao ZH, Zhu H, Cai YJ, Lu W, Ding J. Chk1 and Chk2 are differentially involved in homologous recombination repair and cell cycle arrest in response to DNA double-strand breaks induced by camptothecins. Mol Cancer Ther 2008; 7: 1440-49.

11 Rasheed ZA, Rubin EH. Mechanisms of resistance to topoisomerase I-targeting drugs. Oncogene 2003; 22: 7296-304. 